This item was submitted to Loughborough's Research Repository by the author.

Items in Figshare are protected by copyright, with all rights reserved, unless otherwise indicated.

\title{
Carbon footprint calculator
}

PLEASE CITE THE PUBLISHED VERSION

http://dx.doi.org/10.4135/9781412975704.n23

PUBLISHER

(c) SAGE Publications

VERSION

AM (Accepted Manuscript)

LICENCE

CC BY-NC-ND 4.0

REPOSITORY RECORD

Goodier, Chris I.. 2019. "Carbon Footprint Calculator”. figshare. https://hdl.handle.net/2134/12106. 
This item was submitted to Loughborough's Institutional Repository (https://dspace.lboro.ac.uk/) by the author and is made available under the following Creative Commons Licence conditions.

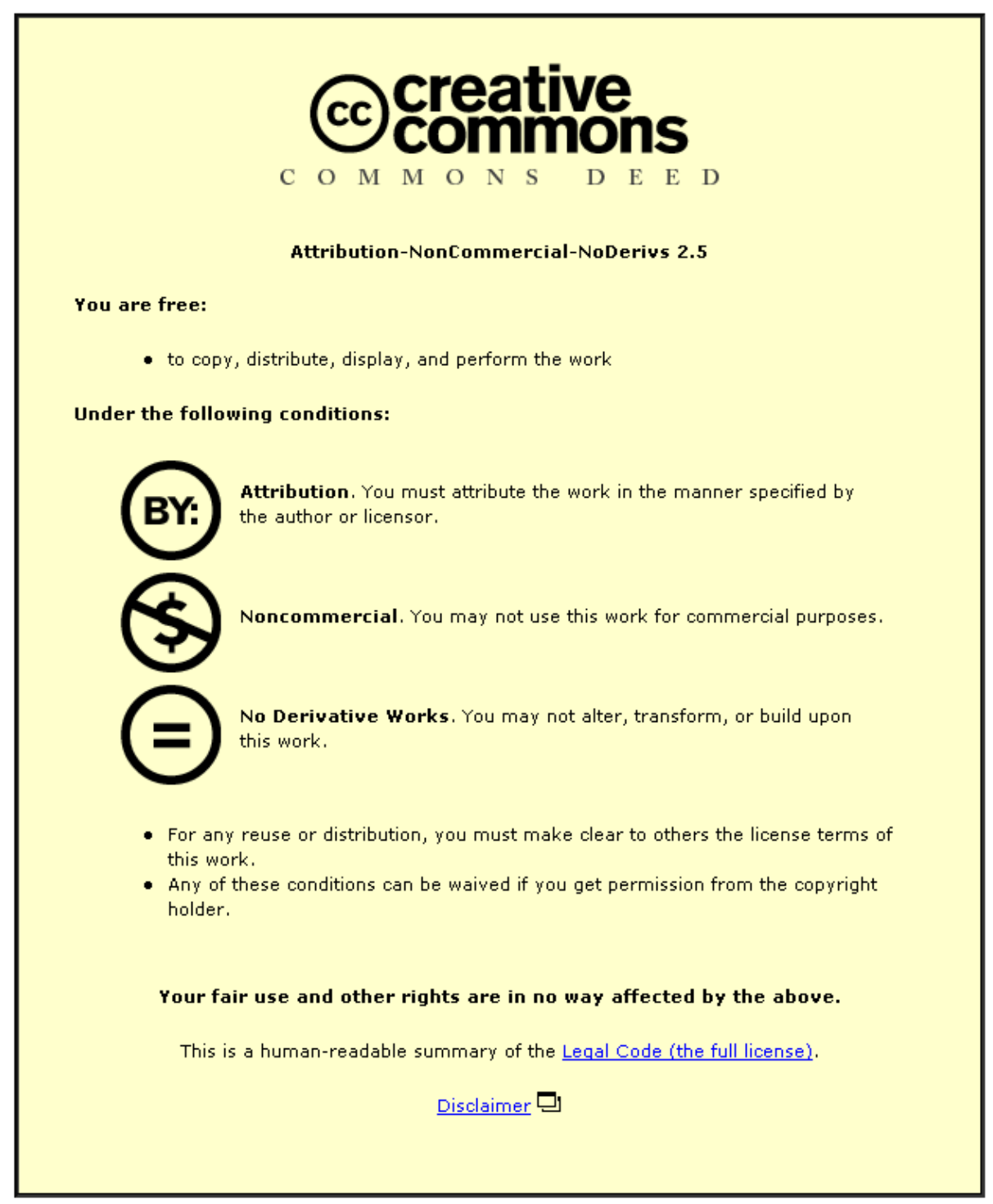

For the full text of this licence, please go to: http://creativecommons.org/licenses/by-nc-nd/2.5/ 


\section{Carbon Footprint Calculator}

The carbon footprint is a measure of the total amount of Carbon Dioxide $\left(\mathrm{CO}_{2}\right)$ and other greenhouse gas emissions that are directly or indirectly caused by an activity, or which are accumulated over the life span of a product, person, an organisation, or even a city or state. Carbon footprinting is a measure by which a company or individual can calculate how much carbon emissions they have produced during a project or time period. Usually there are two major reasons for wanting to determine a carbon footprint - to manage the footprint and reduce emissions over time, and/or to report the footprint accurately to a third party.

Knowing the carbon footprint of an organisation can be an effective tool for ongoing energy and environmental management. If this is the main reason for calculating the carbon footprint, it is often enough just to understand and quantify the key emissions sources through a basic process, typically including gas, electricity and transport, which is relatively quick and straightforward to do. Having quantified these emissions, potential opportunities for carbon reduction can be identified.

Companies and organisations are also increasingly wanting to calculate their carbon footprint in detail for public disclosure e.g. for marketing purposes, to fulfil requests from customers or investors, or to determine what quantity of emissions they need to offset for them to become 'carbon neutral'. This therefore requires a more robust approach, covering the full range of emissions for which the organisation might be responsible.

The basic carbon footprint can be calculated fairly quickly for most organisations. A basic footprint is likely to cover direct emissions and emissions from electricity as these are the simplest to manage, but exclude some of the indirect emissions. Major emissions sources that must be quantified include onsite fuel and electricity usage, and the use of transport which you own. Data must be collected from all utility meters and the distances travelled by the organisation's vehicles must be recorded. The fuel, electricity and transport consumption figures are then converted to $\mathrm{CO}_{2}$ by using standard emissions factors, which in the UK are available from Defra and the Carbon Trust.

A methodology that is popular is the Green House Gases (GHG) Protocol produced by the World Resources Institute (WRI) and the World Business Council for Sustainable Development (WBCSD). This methodology provides detailed guidance on corporate emissions reporting and is available at www.ghgprotocol.org. A more recent standard from the International Organization for Standardization, ISO 14064, also provides guidance on corporate carbon footprint calculation and is available at www.iso.org. The UK has introduced a new measure of $\mathrm{CO}_{2}$ emissions for goods and services to standardise carbon footprint calculations. PAS 2050:2008, the 'Specification for the Assessment of the Life Cycle Greenhouse Gas Emissions of Goods and Services' produced by BSI British Standards, is designed to show customers how much $\mathrm{CO}_{2}$ has been emitted during production, consumption and 
disposal of a range of products. The new calculation, available at www.bsigroup.com/pas2050, will give the first 'life cycle' $\mathrm{CO}_{2}$ measure that is standardised across industry. The measure is the first standardised calculation of green house gas emissions for goods and services which will allow consumers to compare products easily. A variety of carbon footprint calculators exist, many of them online, from organisations such as the:

- UK government (http://actonco2.direct.gov.uk/index.html)

- US government (www.epa.gov/climatechange/emissions/ind_calculator.html)

- WWW (http://footprint.wwf.org.uk/)

\section{Main types of emissions}

An organisation's full carbon footprint encompasses a wide range of emissions sources from direct use of fuels to indirect impacts such as employee travel or emissions from other organisations up and down the supply chain. When calculating an organisation's footprint it is important to try and quantify as full a range of emissions sources as possible in order to provide a complete picture of the organisation's impact. In order to produce a reliable footprint, it is important to follow a structured process and to classify all the possible sources of emissions thoroughly. A common classification is to group and report on emissions by the level of control which an organisation has over them. A standard classification is defined by the Greenhouse Gas Protocol, a widely utilised standard for corporate emissions reporting produced by the World Business Council for Sustainable Development and the World Resources Institute. Three main types of emissions exist:

- Emissions that result from activities that the organisation controls. The majority of direct emissions will result from combustion of fuels which produce $\mathrm{CO}_{2}$ emissions, e.g. the gas used to provide heating for a building.

- Emissions from the use of electricity. E.g. electricity for lighting and equipment, and electricity generation - in the UK around $75 \%$ is produced through the combustion of fossil fuels such as coal and gas.

- Indirect emissions from products and services. Each product or service purchased by an organisation contributes towards emissions. The way the organisation uses products and services therefore affects its carbon footprint.

Incorporating all three types of emissions in a carbon footprint calculation can therefore be a complex task. In addition, published carbon footprints are rarely comparable for several reasons:

- despite emerging international standards not all organisations follow the same methodology to calculate their carbon footprint

- some carbon footprints are expressed on a time period basis, such as annually, and some are measured on a unit basis, such as per product produced

- carbon footprints are usually calculated to include all greenhouse gases and are expressed in tonnes of $\mathrm{CO}_{2}$ equivalent $\left(\mathrm{tCO}_{2} \mathrm{e}\right)$. Some however, calculate the carbon footprint to include $\mathrm{CO}_{2}$ only and express the footprint in $\mathrm{tCO}_{2}$ (tonnes of $\mathrm{CO}_{2}$ ). 


\section{Carbon Neutral}

This term is commonly used for something having net zero emissions e.g. an organisation or product). As the organisation or product will normally have caused some greenhouse gas emissions, it is usually required to use carbon offsets in order to achieve neutrality, which are emissions reductions that have been made elsewhere and which are then sold to the organisation that seeks to reduce its impact. Carbon neutral can be anything from a person, to a building, to an organisation, or even a city or state - the Vatican in Rome is quickly moving to become the first "carbon neutral state" with the installation of solar panels and the planting of a 37 acre forest in Europe, which is hoped to offset up to 80 tonnes of $\mathrm{CO}_{2}$ a year.

\section{How to Reduce the Carbon Footprint}

A variety of methods exist for reducing an individuals or an organisations carbon footprint. Planting trees is one of the most common and simplest forms of carbon footprint reduction as trees absorb $\mathrm{CO}_{2}$ from the atmosphere. Recycling waste materials such as household, industrial and construction waste is also beneficial as the carbon content of the new materials which would have otherwise been used can be offset. Many energy saving technologies also exist which can contribute towards carbon footprint reduction, from cheap and simple measures such as installing lowenergy light bulbs to more expensive measures such as using electric vehicles. Renewable energy generation can also be used for offsetting a carbon footprint, such as wind turbines and solar panels.

\section{See Also:}

Carbon neutral, Carbon trading, Sustainability Indicators, Sustainable Development, Energy Efficiency

\section{Bibliography}

Online carbon footprint calculators (all accessed August 2010):

- UK government (http://carboncalculator.direct.gov.uk/index.html)

- US government (www.epa.gov/climatechange/emissions/ind_calculator.html)

- WWW (http://footprint.wwf.org.uk/)

British Standards Institute (BSI), PAS 2050:2008, Specification for the assessment of the life cycle greenhouse gas emissions of goods and services, UK, available online at www.bsigroup.com/pas2050, 2008, (accessed August 2010).

Brown, M.A., Southworth F., and Sarzynski, A., Shrinking the Carbon Footprint of Metropolitan America, USA, p83, Brookings, available online at www.blueprintprosperity.org, 2008, (accessed August 2010).

Global Footprint Network, available online at www.footprintnetwork.org, (accessed August 2010). 
Greenhouse Gas Protocol (GHG Protocol), available online at www.ghgprotocol.org/, (accessed August 2010).

International Organization for Standardization (ISO), ISO 14064-1:2006,

Greenhouse Gases Part 1: Specification with guidance at the organization level for quantification and reporting of greenhouse gas emissions and removals, available online at www.iso.org (accessed August 2010).

Dr Chris Goodier

Loughborough University 